\title{
Multiple Chorangioma Following Long-Term Secondary Infertility: A Rare Case Report and Review of Pathologic Differential Diagnosis
}

This article was published in the following Dove Press journal:

International Medical Case Reports Journal

\author{
Mojgan Akbarzadeh- \\ Jahromi \\ Neda Soleimani (iD \\ Sahand Mohammadzadeh \\ Department of Pathology, Shiraz \\ University of Medical Sciences, Shiraz, \\ Iran
}

\begin{abstract}
Chorangioma (placental hemangioma) is a benign non-trophoblastic neoplasm of the placenta. Small chorangiomas are usually asymptomatic, but the giant and multiple ones rarely have a favorable outcome. We report a case of 29 weeks of gestational age (after longterm secondary infertility) with premature labor pain and undiagnosed multiple chorangioma leading to hydrops fetalis and neonatal death. Here we report the clinicopathological features of our case and chorangioma in general, along with comparison of different vascular lesions of placenta in terms of incidence, risk factors, complications, histologic origin, macroscopic and light and electron microscopic features.
\end{abstract}

Keywords: chorangioma, chorangiomatosis, chorangiosis

\section{Introduction}

Chorangioma (placental hemangioma) is a benign non-trophoblastic neoplasm of the placenta, having an incidence of $1 \%$ on gross pathological examination. Most placental chorangiomas are small and located entirely in placental substance, that is why they could be missed easily unless the placenta is systematically sliced after delivery. ${ }^{1,2}$ Small chorangiomas are usually asymptomatic, but the giant and multiple ones rarely have favorable outcome. So prenatal diagnosis would help to predict the pregnancy outcome and taking interventions if possible. We hereby present a case of 29 weeks of gestational age with undiagnosed multiple chorangioma and neonatal death.

\section{Case Report}

A woman aged 31, G2P0A1, at 29 weeks of gestation was admitted to the emergency center of Obstetrics and Gynecology department of Shiraz University of Medical Sciences, Iran, due to premature labor pain. Current pregnancy had occurred spontaneously after a long period of secondary infertility (12 years). There was a notable history of failed IUI (intra uterine insemination) 12 years ago. During this long time no study was done to evaluate the cause of infertility. She also had a history of appendectomy before marriage. Pelvic examination revealed active phase delivery and due to no beat-to-beat NST (non stress test), emergency cesarean section (c/s) was performed with the birth of a poor Apgar girl weighing $1250 \mathrm{~g}$ with gross features of hydrops fetalis. Unfortunately she had only one normal obstetric sonography which was done early in pregnancy. Additional follow up of the neonate showed dilated cardiomyopathy and she passed away after 14 days. The placenta which was sent for pathologic examination, weighed
Correspondence: Neda Soleimani Department of Pathology, Shiraz University of Medical Sciences, Shiraz, Iran

Tel +989173422519

Fax +987132301784

Email neda_soleimani6I@yahoo.com 
$450 \mathrm{~g}$ and placental disc measured $16 \mathrm{~cm}$ in greatest diameter and $2 \mathrm{~cm}$ in maximal thickness with membranous insertion of umbilical cord. Furthermore it revealed multiple well circumscribed creamy rubbery masses measuring from 0.2 to $4 \mathrm{~cm}$ at maternal surface (Figure 1). Microscopic examination of different nodules showed well demarcated lesions composed of numerous capillary sized vascular channels that were covered by trophoblastic layers (Figures 2-4).

Written informed consent has been provided by the patient for publication of this case report, including images. Our institutional approval is not required to publish the case details.

\section{Discussion}

With rare exception, vascular tumors are the only benign tumors of the placenta. ${ }^{3}$ Chorangioma and chorangiosis are two sides of a spectrum that pass through chorangiomatosis. They are lesions of capillary dysvasculogenesis

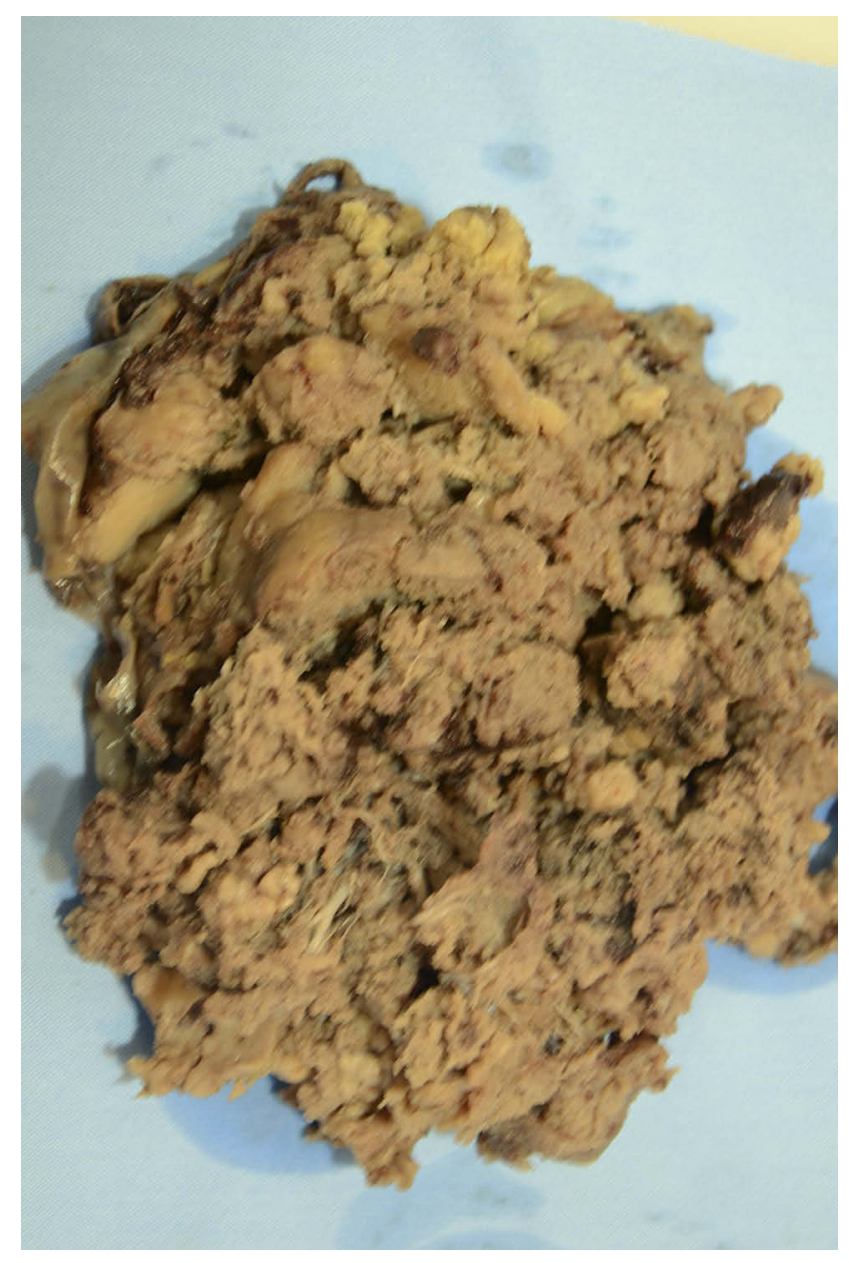

Figure I Gross features of placenta show multiple well defined rubbery nodules located on the chorionic plate.

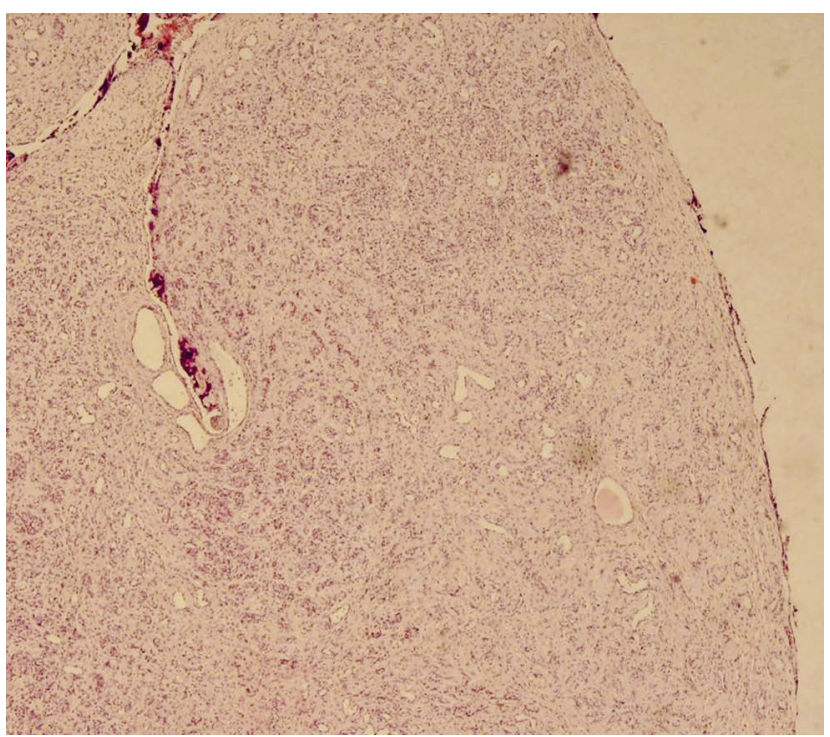

Figure 2 Microscopic examination of one nodule showing a well demarcated vascular lesion resembling capillary hemangioma $(H \& E \times 10)$.

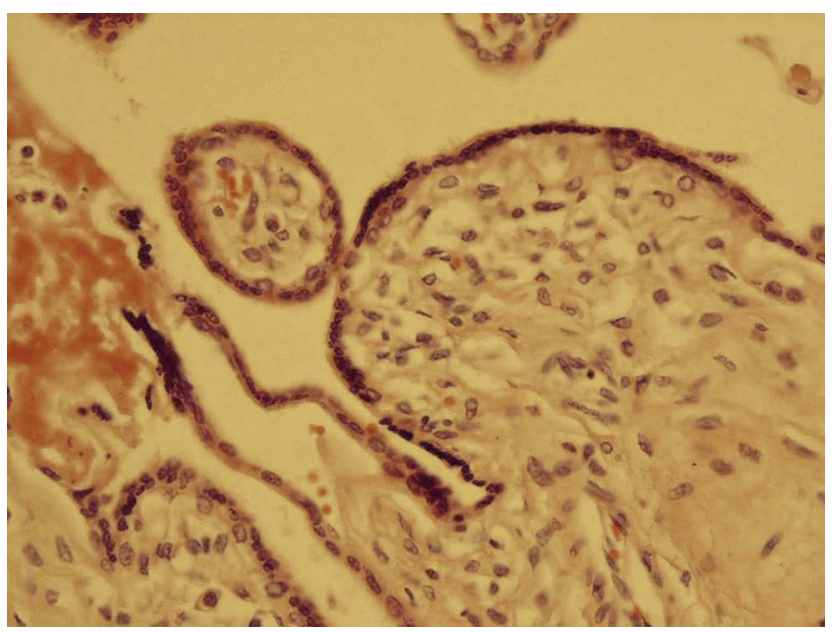

Figure 3 The lesion is covered by a trophoblastic layer (H\&E $\times 40)$.

with different clinical presentation and complications, however some overlapping features are always present (Table 1).

Hypoxia may lead to excessive villous capillary growth and proliferative activity of connective tissue, probably mediated by vascular growth factors. ${ }^{6}$ That is why chorangiomas tend to be in areas with hypoperfusion and chorangiosis is a secondary process involving a response of the placenta to fetal hypoxia. ${ }^{11}$ In our case previous abortion and IUI could be considered as the cause, since they can create hypoperfused areas in the uterus.

Chorangiomas are often seen as solitary nodules, mostly buldging from the fetal surface of the placenta or 


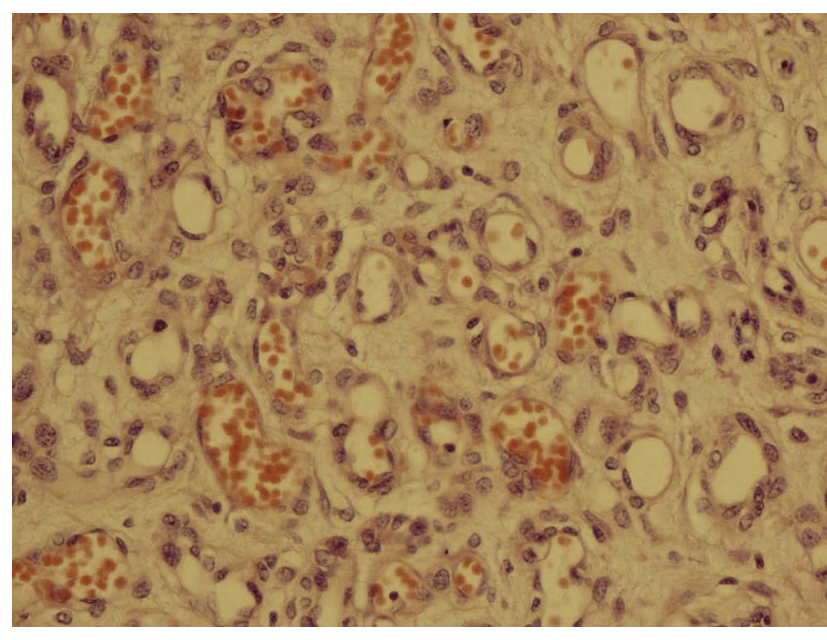

Figure 4 Numerous capillary sized vascular channels (H\&E $\times 40)$.

attached to the placental disc by a pedicle with a greater frequency in less perfused areas such as chorionic plate and placental margins. ${ }^{1,12}$

They are usually small and microscopic but multiple and larger ones have also been found with 26x20x12 cm size in the largest reported case. ${ }^{13}$

Grossly, chorangiomas are sharply circumscribed from the surrounding parenchyma. Usually there is a fleshy, congested, red/tan cut surface with occasional presence of myxoid, fibroma-like or degenerative changes. ${ }^{1}$
Microscopically, it shows a well-defined lesion arising from stem villi composed entirely of blood vessels within a cellular stroma and often surrounded by trophoblasts. ${ }^{1}$

Histologic variants include: capillary, cavernous, endotheliomatous, fibrosing and fibromatous, among these, capillary type is the most frequent histological type. ${ }^{14}$

Sometimes there is association of degenerative changes such as hemosiderin deposition, hyalinization and also calcification. ${ }^{1}$

The sonographic appearance of chorangioma is a welldefined predominantly hypoechoic mass. Color Doppler imaging can define the presence of a single feeding blood vessel with branching pattern and could contribute to rule out other uterine pathologies with similar sonographic appearances, such as placental hemorrhage, subchorionic hematoma, myoma, placental teratoma, and molar pregnancy. MRI could also be helpful in chorangioma management. ${ }^{12,13}$

The rate of occurrence rises in women over 30 years, presence of diabetes, hypertension, twin pregnancies (both monozygous and dizygous), maternal smoking and living at high altitude. ${ }^{8-10}$

While small chorangiomas are usually asymptomatic, the multiple and larger ones (greater than $4 \mathrm{~cm}$ ), can induce significant effects on hemodynamic and circulatory processes of the fetus with overall mortality rate of $30 \% .{ }^{15}$

Table I Clinical Features of Different Vascular Lesions of Placenta

\begin{tabular}{|l|l|l|l|l|l|}
\hline Lesion & Incidence & Gross Features & Origin & Risk Factors** & Complications** \\
\hline Congestion & $*$ & $\begin{array}{l}\text { No distinct gross } \\
\text { abnormality }\end{array}$ & $*$ & $*$ & No complication \\
\hline Chorangiosis & Variable & $\begin{array}{l}\text { No distinct gross } \\
\text { abnormality }\end{array}$ & $\begin{array}{l}\text { Terminal } \\
\text { villi' }\end{array}$ & $\begin{array}{l}\text { Pre-eclampsia, DM, drug ingestion, UTI } \\
\text { multiple gestation, } \\
\text { smoking }\end{array}$ & $\begin{array}{l}\text { IUGR, IUFD, fetal } \\
\text { malformation, c/s }\end{array}$ \\
\hline Chorangiomatosis & $0.55^{4}$ & $\begin{array}{l}\text { Heterogenous and } \\
\text { less well defined } \\
\text { lesions }\end{array}$ & $\begin{array}{l}\text { Mature } \\
\text { stem } \\
\text { villi' }\end{array}$ & Pre-eclampsia, multiple gestation and prematurity & $\begin{array}{l}\text { IUGR }{ }^{8} \text { Premature } \\
\text { delivery }\end{array}$ \\
\hline Chorangioma & $1 \%{ }^{1}$ & $\begin{array}{l}\text { Small solitary well } \\
\text { defined nodule }\end{array}$ & $\begin{array}{l}\text { Mature } \\
\text { stem } \\
\text { villi' }\end{array}$ & $\begin{array}{l}\text { Women over 30 years, HTN, twin pregnancy, } \\
\text { maternal smoking and living at high altitude }\end{array}$ & $\begin{array}{l}\text { Premature } \\
\text { delivery } \\
\text { Heart failure } \\
\text { Fetal hydrops } \\
\text { MHA, IUFD }{ }^{\prime \prime}\end{array}$ \\
\hline $\begin{array}{l}\text { Atypical } \\
\text { chorangioma }\end{array}$ & Very rare & $\begin{array}{l}\text { Solitary well defined } \\
\text { nodule }\end{array}$ & $\begin{array}{l}\text { Mature } \\
\text { stem villi }\end{array}$ & Undetermined & Undetermined \\
\hline
\end{tabular}

Notes: *Not applicable. **There is some overlapping between different lesions.

Abbreviations: LPF, low power field; MHA, microangiopathic hemolytic anemia; DM, diabetes mellitus; HTN, hypertension; IUFD, intra uterine fetal death; IUGR, intra uterine growth retardation; MHA, microangiopathic hemolytic anemia. 
Table 2 Histological Differences Between Different Vascular Lesions of Placenta

\begin{tabular}{|c|c|c|}
\hline Lesion & Light Microscopy & Electron Microscopy \\
\hline Congestion & Prominent capillaries, but the vasculature is numerically normal ${ }^{22}$ & No specific change \\
\hline Chorangiosis & $\begin{array}{l}\text { A diffuse process }>10 \text { capillaries in }>10 \text { terminal villi in at least } 10 \\
\text { different non-infarcted areas in } 3 \text { LPF }^{20} \\
\text { All vessels have the same caliber }\end{array}$ & $\begin{array}{l}\text { Each capillary is surrounded by a distinct } \\
\text { basement membrane } \\
\text { Lack of MSA-positive pericytes around the vessels } \\
\text { Lack of lattice-like pattern of reticulin fiber' }\end{array}$ \\
\hline Chorangiomatosis & $\begin{array}{l}\text { III-defined proliferation of variable sized capillaries (concentrated in the } \\
\text { center of villi) surrounded by circumferential layer of pericytes }{ }^{8}\end{array}$ & $\begin{array}{l}\text { No distinct basement membrane } \\
\text { Bundles of reticulin fibers surround capillaries }\end{array}$ \\
\hline Chorangioma & $\begin{array}{l}\text { Well defined proliferation of capillary sized blood vessels and surface } \\
\text { trophoblastic proliferation }\end{array}$ & $\begin{array}{l}\text { No distinct basement membrane } \\
\text { Continuous layer of MSA-positive pericytes around } \\
\text { each vessel } \\
\text { Bundles of reticulin fibers will merge in the } \\
\text { surrounding villous stroma in a lattice-like loose } \\
\text { pattern' }\end{array}$ \\
\hline $\begin{array}{l}\text { Atypical } \\
\text { Chorangioma }\end{array}$ & $\begin{array}{l}\text { Similar to chorangioma plus increased cellularity, mitotic activity and } \\
\text { areas of necrosis } 5\end{array}$ & $\begin{array}{l}\text { Similar to chorangioma plus mitosis and (or) } \\
\text { necrosis }\end{array}$ \\
\hline
\end{tabular}

More vascular and hypoechoic tumors are associated with higher incidence of pregnancy complications. ${ }^{16}$

Rare occurrence of recurrent chorangiomas poses the role of genetics in its creation. In the few published instances of recurrent chorangioma, the masses were always multiple or even numerous. ${ }^{17}$

Association with Beckwith-Wiedemann syndrome, placental mesenchymal dysplasia and concurrence of multiple chorangiomas with fetal hepatic hemangioendothelioma have been reported. ${ }^{18}$

As we know, pregnancies with the most serious complications often present in the late second trimester, at which time delivery is not an option. It seems that treatment with intrauterine transfusion could be a preventive intervention. ${ }^{12,19-21}$

Microscopically normal placental villi should contain no more than 5 vascular channels, even when the same vessel is present in more than one plane of section. Table 2 shows histological differences between different vascular lesions of placenta in examination using light and electron microscopy.

Congestion is sometimes confused with vascular tumors at first glance microscopically.

Chorangiomatosis in the focal variant is similar to chorangioma and in the diffuse multifocal form shares some features with chorangiosis. ${ }^{23}$

To our knowledge by far only rare cases of true multiple chorangiomas, like ours, have been reported and most cases which are reported as multiple chorangioma are just diffuse chorangiomatosis due to lack of well circumscribed nodules.

\section{Conclusion}

Vascular lesions of the placenta are in fact a spectrum of variable lesions with some common clinical and pathologic features and from chorangiosis to chorangioma the outcome is worse, especially in multiple and large lesions.

\section{Disclosure}

The authors report no conflicts of interest in this work.

\section{References}

1. Amer HZ, Heller DS. Chorangioma and related vascular lesions of the placenta. Fetal Pediatr Pathol. 2010;29(4):199-206. doi:10.3109/ 15513815.2010.487009

2. Gruca-Stryjak K, Ropacka- Lesiak M, Breborowicz G. [Intrauterine blood transfusion in case of placental chorangioma]. Ginekol Pol. 2011;82(4):304-308.

3. Corcoran CJ, Murphy EC. Rare bovine placental tumor- a case report. Vet Rec. 1965;77:1234-1235. doi:10.1136/vr.77.42.1234

4. Garg S. Chorangiomatosis. PathologyOutlines.com website. Available from: http://www.pathologyoutlines.com/topic/placentachorangiomato sis.html. Accessed August 12, 2019.

5. Vellone VG, Calamaro P, Vignale C, Novaro G, Penna L, Fulcheri E. Atypical cellular chorangioma: a potential diagnostic pitfall with worrisome aspects but a favorable prognosis. Int J Surg Pathol. 2015;23 (5):364-368. doi:10.1177/1066896915585347

6. Caldarella A, Buccoliero AM, Taddei GL. Chorangiosis: report of three cases and review of the literature. Pathol Res Pract. 2003;199:847-850. doi:10.1078/0344-0338-00506

7. Suzuki K, Itoh H, Kimura $\mathrm{S}$, et al. Chorangiosis and placental oxygenation. Congenit Anom (Kyoto). 2009;49(2):71-76. doi:10.1111/ j.1741-4520.2009.00226.x

8. Momeni Boroujeni A, Yousefi E, Vincent MT, Anderson V. Chorangiomatosis: evaluation of a placental vascular lesion and related clinical effects. Fetal Pediatr Pathol. 2014;33:331-338. doi:10.3109/ 15513815.2014.977620 
9. Hoeger PH, Maerker JM, Kienast AK, Syed SB, Harper JI. Neonatal hemangiomatosis associated with placental chorangiomas: report of three cases and review of the literature. Clin Exp Dermatol. 2009;34 (5):78-80. doi:10.1111/j.1365-2230.2009.03221.x

10. Sepulveda W, Alcalde JL, Schnapp C, Bravo M. Perinatal outcome after prenatal diagnosis of placental chorangioma. Obstet Gynecol. 2003;102:1028-1033. doi:10.1016/s0029-7844(03)00859-7

11. Fox H. Vascular tumors of the placenta. Obstet Gynecol Surv. 1967;22(5):697-711. doi:10.1097/00006254-196710000-00001

12. Zalel Y, Gamzu R, Weiss Y, et al. Role of color doppler imaging in diagnosing and managing pregnancies complicated by placental chorangioma. J Clin Ultrasound. 2002;30(5):264-269. doi:10.1002/ jcu. 10072

13. Batukan C, Holzgreve W, Danzer E, Burder E, Hosil I, Tercanli S. Large placental chorangioma as a cause of sudden intrauterine fetal death. A case report. Fetal Diagn Ther. 2001;16(6):394-397. doi:10.1159/000053946

14. Adil SAK, Shilpa K, Bharthi M, Anubha A. Giant extraplacental chorangioma: a case report and review. J Evol Med Dent Sci. 2012;1(4):298-301. doi:10.14260/jemds/49

15. Shafqat G, Iqbal F, Rizvi F. Chorangioma of the placenta with hydrops fetalis. J Pak Med Assoc. 2009;59(6):411-412.
16. Guschmann M, Henrich W, Entezami M, Dudenhausen JW. Chorangioma- new sights into a well known problem. J Perinat Med. 2003;31:163-169. doi:10.1515/JPM.2003.022

17. Feroehlich LA, Fujikura T, Fisher P. Chorangiomas and their clinical implications. Obstet Gynecol. 1971;37:51-59.

18. Benirschke K. Recent trends in chorangiomas, especially those of multiple and recurrent chorangiomas. Pediatr Dev Pathol. 1999;2 (3):264-269. doi:10.1007/s100249900122

19. Chan KW, Leung CY. Recurrent multiple chorangiomas and intrauterine death. Pathology. 1988;20:77-78. doi:10.3109/00313028809085204

20. Shalev E, Weiner E, Feldman E, Zuckerman HK. Prenatal diagnosis of placental hemangioma clinical implication: a case report. Int J Gynaecol Obstet. 1984;22:291-293. doi:10.1016/0020-7292(84)90085-7

21. Zanardini C, Papageorghiou A, Bhide A, Thilaganathan B. Giant placental chorangioma: natural history and pregnancy outcome. Ultrasound Obstet Gynecol. 2010;35:332-336. doi:10.1002/uog.7451

22. Altshuler G. Chorangiosis: an important placental sign of neonatal morbidity and mortality. Arch Pathol Lab Med. 1984;108:71-74.

23. Ogino S, Redline RW. Villous capillary lesions of the placenta: distinctions between chorangioma, chorangiomatosis, and chorangiosis. Hum Pathol. 2000;31(8):945-954. doi:10.1053/hupa.2000.9036

\section{Publish your work in this journal}

The International Medical Case Reports Journal is an international, peer-reviewed open-access journal publishing original case reports from all medical specialties. Previously unpublished medical posters are also accepted relating to any area of clinical or preclinical science. Submissions should not normally exceed 2,000 words or 4 published pages including figures, diagrams and references. The manuscript management system is completely online and includes a very quick and fair peer-review system, which is all easy to use. Visit http://www.dovepress.com/testimonials.php to read real quotes from published authors. 